\title{
A FRAMEWORK OF AGENT-BASED SUPPLY CHAIN PERFORMANCE ANALYSIS SYSTEM
}

\author{
Guannan Qu, Zhiyi Fang \\ School of Computer Science and Technology, Jilin University \\ Changchun, 130012, P.R China \\ qgn_0316@163.com,zyfang@public.cc.jl.cn \\ Chao Zhang \\ College of Economy and Information, Jilin University \\ Changchun, 130012, P.R China \\ zhangchao_m47@sina.com
}

\begin{abstract}
Supply chain management is a popular trend for intensive global competition, and the performance analysis plays an important role in improving supply chain. This paper introduces the basic of the supply chain management and performance analysis. We emphasize the importance of building the performance analysis system to evaltate the entire supply chain. Via reviewing the characteristics of supply chain and challenges in supply chain performance analysis, we design a framework of performance analysis system to meet the challenges in supply chain performance evaluation, and then give an application in this paper.
\end{abstract}

\section{INTRODUCTION}

Intensive global competition, faster product development, increasingly flexible manufacturing system, an unprecedented number and variety of products are the characteristics of today's global market (Simichi et al., 2000). Supply Chain Management, as a new mode of management, is becoming a more and more challenging task in such an uncertain world. Lambert and Cooper (2000) defined the Supply Chain Management (SCM) as the management of relationships across a supply chain to capture the synergy of intra- and inter-company business process which referred to as supply chain management.

Performance analysis for the supply chain is an important part of the SCM (Supply Chain Management), and it mainly aims at (Xu et al., 2004): (1) carrying on the appraisal to the performance of the entire supply chain, which provides the proof of making the strategy for core enterprise; (2) evaluating the business process, and bottleneck in the supply chain which will be found and conquered; (3) examining the 
node in supply chain, and presenting the status of the node corporations, which can help to establish more reasonable symbiosis.

Currently, the design and development of supply chain performance analysis system exhibits two trends. First, some systems put the performance evaluation as a choice into the related part, such as sale performance, which is taken as a part of sale management module in supply chain. It does a good job on collecting information in time but against adapting diverse performance metrics, and it fails in building multicriteria. The second trend is to build unattached performance system while ignoring its context--supply chain, which facilitates rebuilding and updating performance measures, yet makes it more difficult to gather dynamic data.

In this work, we combine these two trends and explore the performance analysis system, which correlates with supply chain management system. Although, it is autonomic, namely, the operation of managing criteria and calculating is independent, however, the information that is used to do analysis should be collected from the in time running of supply chain through communicating between agents, and the analysis result impacts the SCM structure and configuration directly so that adjustment and optimization of the SC could be achieved.

This rest of the paper is organized as follows: in Section 2, we analyze the characteristics of supply chain and challenges in supply chain performance analysis. The framework of the agent-based performance analysis system will be illustrated in Section 3. In Section 4, we use this framework in an application and demonstrate it by an example.

\section{CHALLENGE OF CONSTRUCTING PERFORMANCE ANALYSIS SYSTEM}

Historically, Enterprises have focused only on their resources, constrains, and policies to make decisions and reduce costs. With intense competition and reducing profit margins, this approach is no longer sufficient. They need to consider the interactions with their suppliers and customers and incorporate them into their decision-making process (Julka et al., 2002). The aim of performance analysis is analyzing and evaluating the process and the outcome of the entire supply chain using appropriate approaches.

In this situation, there are several challenges in constructing supply chain management system and its performance analysis system. The first challenge is from the characteristics of supply chain, since it is the information source of performance analysis. Secondly, how to evaluate the performance of entire supply chain comprehensively should be taken into consideration. Finally, the performance analysis system should adapt to different performance measures designing and continuously updating. These are now described in turn.

\subsection{Characteristics of Supply Chain Elements}

We identify the elements in a supply chain, their features, and the challenges associated with SCM, and these are the foundation of modeling the performance 
analysis system (Chai and Liu, 2001). The elements in supply chain can be classified as entities and flows. Entities include all manufacturers, logistics providers, electronic exchanges and all their internal departments that participate in the business process. These entities are essentially the operators in the supply chain. Flows are of three types - material, information and finance, and these are the operands in the supply chain. These entities have four common features:

1) Dynamic: The supply chains are more flexible now. In today's business environment, there are no obligations for companies to be part of supply chain for certain time period and they may join or leave based on their own interest. This changes the structure and flows in the supply chain. Information in the supply chain, such as prices, demands, technologies, etc, is also changing continuously.

2) Distributed: The elements are distributed across various geographical locations. The planning and operating systems used by an entity may also be geographically distributed. For example, there may be a dedicated inventory database residing at each warehouse of a manufacturer. The SCM related information might even reside as rules-of-thumb with the people responsible for performing the various tasks in the business process.

3) Disparate: The entities in a supply chain use different systems built on different platforms for planning and management of their business. Information pertaining to the various elements is also disparate in form.

4) Cooperative: Cooperating closely between the enterprises or enterprise interior is emphasize in supply chain, e.g. a certain affair possibly involves to design, manufacture, purchase, transportation and so on, and these need the relevant units' cooperating inevitably.

Unfortunately, information needed by performance analysis sourced from these dynamic, distributed and disparate entities and flows, passing through the actions and the reached results.

\subsection{Comprehensive performance evaluation}

Entities in supply chain will make their own decision, which are usually based on their own constrains. Most often, the decisions are taken independent of the interdependency factors contributing to the overall business process of the enterprise. So the performances are optimized locally within the departments but do not assure a global optimum for the enterprise.

Multi-criteria is an integrated evaluation system, and it is constructed by some criteria in terms of given authority. For example: Yahya and Kingsman (1999) use Satty's ananlytic hierarchy process (AHP) method to determine priority in selecting suppliers, as show as Figure. 1 (Liu et al., 2005).

The problem is to evaluate the comprehensive performance of suppliers. On the top level is the overall goal of selection suppliers. On the second level are eight criteria that contribute to the goal. On the third level are eight criteria that are decomposed into 13 subcriteria, and on the bottom level are to be evaluated in terms of the subcriteria of the third level. 


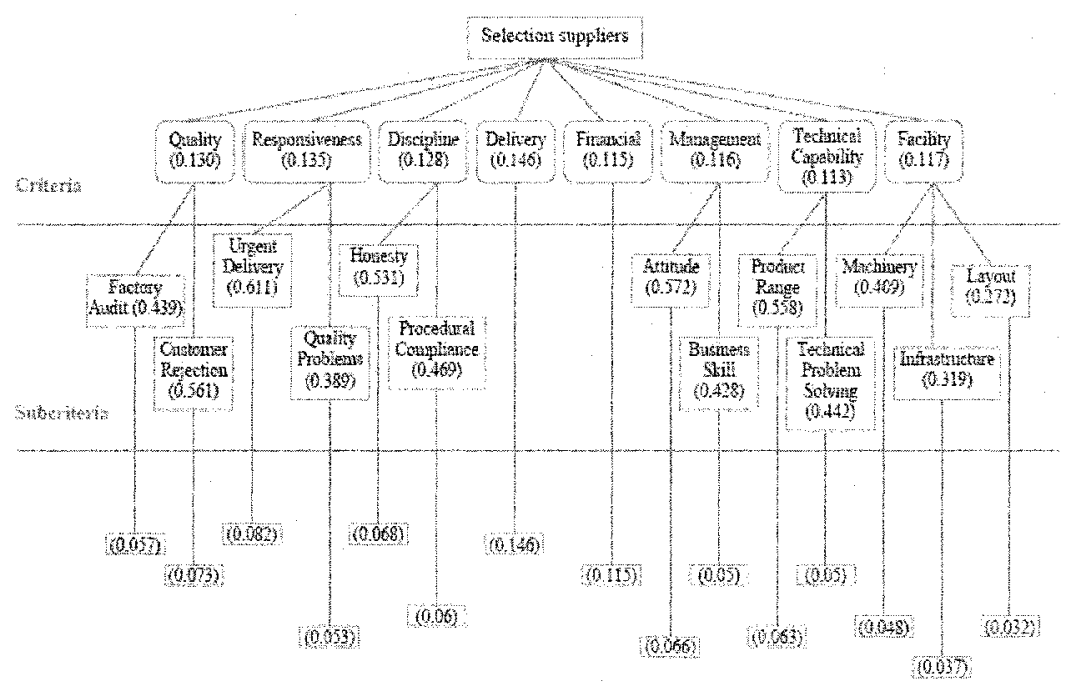

Figure 1. Hierarchy of selection suppliers

\subsection{Performance Metrics}

There are a large number of different types of available performance measures and a given supply chain could select appropriate performance analysis system for themselves (Beamon, 1999). Such as, for an electronic industry, which is interpreted as a fast-moving industry, how can its supply chain be measured? An appropriate performance analysis system should be selected.

On the other hand, with further study and practice on performance metrics, the issues of continuously updating the performance measures and the analysis systems also should be taken into mind.

Mike Bourne et al. (2000) summed up three phases of developing performance analysis systems:

1) The design of the performance measures;

2) The implementation of the performance measures;

3) The use of the performance measures

The design phase can be subdivided into identifying the key objectives to be measured and designing the measures themselves; implementation is defined as the phase in which data that enable the performance measures to be made regularly should be collect and process; the use of performance measures to test the analysis system itself on one side, on the other hand, it is used to analysis the performance of entire supply chain.

We have introduced the challenges of supply chain performance analysis; next section will address these critical needs by presenting a framework of agent-based supply chain performance analysis system, which is better founded on agent-based 
supply chain management system. This framework focuses on building a system which meets the demands of each phase of developing performance measures and making it easier to rebuild and update. It obtains information actively and timely from supply chain via agent, and simultaneously manages the criteria and multicriteria templates independently.

\section{FRAMEWORK OF THE AGENT-BASED PERFORMANCE ANALYSIS SYSTEM}

In fact, performance analysis is part of supply chain management, for its information derives from the operation activities of supply chain and each entity, on the contrary, its analysis result takes effect on the supply chain.

We construct a framework of agent-based supply chain performance analysis system, Showed as Figure 2, to overcome the challenges mentioned in last section, and we will explain the main parts of this system in turn.
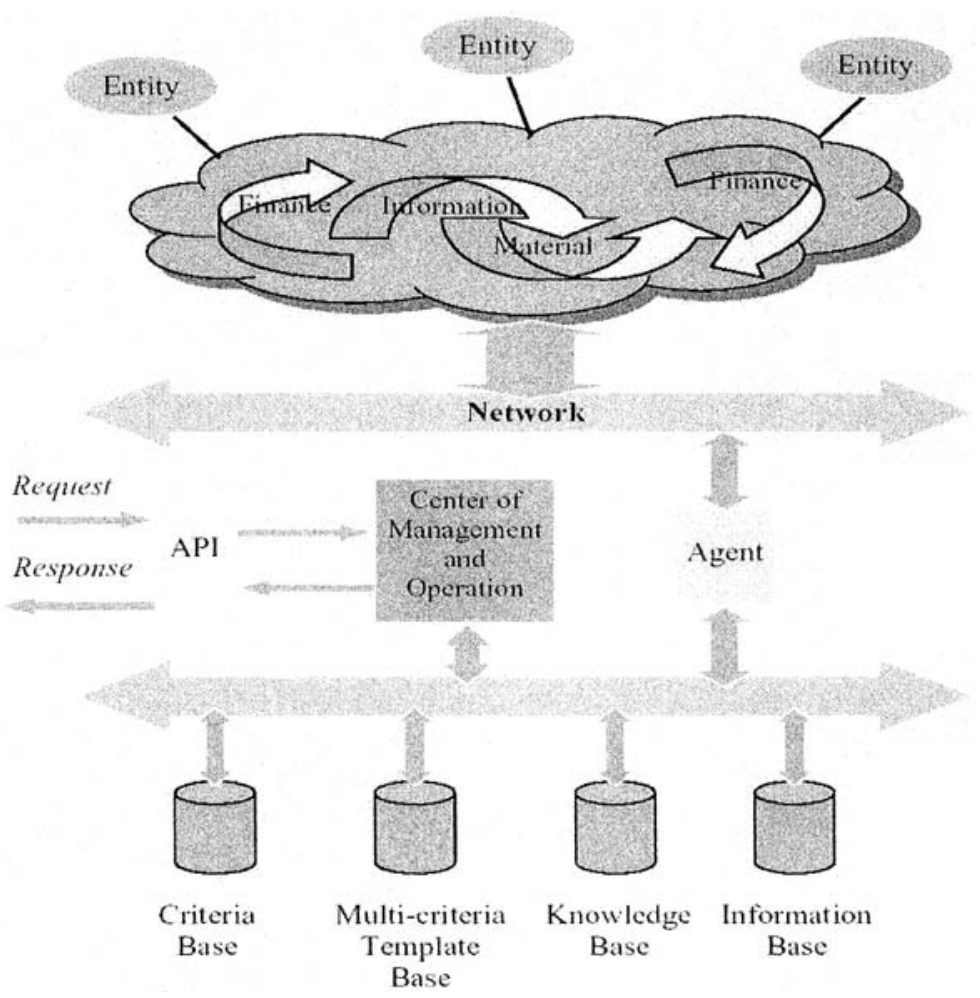

Figure 2. Framework of the agent-based performance analysis system 
The whole performance analysis is base on a series of primary issues of the criteria, multi-criteria, analysis operations and criteria management, and information collection. The performance analysis of the supply chain could be reduced to several main parts as follow:

(1) Criteria

Criteria are the most elementary factors in supply chain analysis, and they are monomials. In another word, each type of criteria only appraises a given segment of the supply chain. For example, Percentage of Repairing and Exchanging Purchase is defined as the rate of the products that need to be returned and repaired in a given time, and it reflects quality of the products.

Managing these criteria seemed to be very simple, however, there are two issues to be settled. The first is the category of criteria. Base on the diverse evaluating methods and sustainable development of performance analysis, category of criteria may be added, deleted or modified, although it is relatively stable to a given supply chain.

The second issue is the operands of the criteria. For example, Loyalty of Retailer is defined as:

$$
R_{f}=\frac{h}{m} \times 100 \%
$$

There are two variables in this expression $-\mathrm{h}$ and $\mathrm{m} . \mathrm{h}$ is the number of the retailer who drops out the certain supply chain to seek new supplier in a given time; $\mathrm{m}$ is the sum of retailers initially. These operands are obtained from the elements of supply chain - entity and flow. Unfortunately, the entities of supply chain are dynamic, distributed and disparate. Given this reality, there is a clear need for an agent (Wooldridge and Jennings, 1994), which is capable of gathering the dynamic and disparate information required for performance analysis.

Figure 3 shows the class of criteria and its rules, and agent obtains data in terms of these rules, which are preserved in knowledge base.

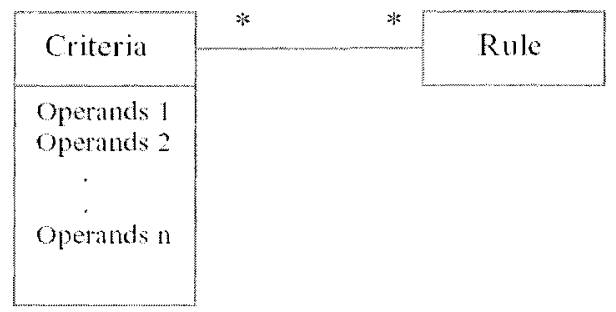

Figure 3. Class of criteria and its rules

\section{(2) Multi-criteria}

Multi-criteria is an integrated evaluation system, which is reconstructed by certain criteria in terms of given authority, according to some strategy. It is used to analyze the comprehensive result of the whole or integrant supply chain operation. The 
establishment of the multi-criteria needs the experts involving in this domain. Yet it is also needs to be added or cancelled flexibly.

However, we don't care how to develop the multi-criteria rather than identifying some templates of the multi-criteria as files. The experts have built these multicriteria, and we just focus on managing and using these templates.

Figure 4 shows the relation between Multi-criteria template and criteria.

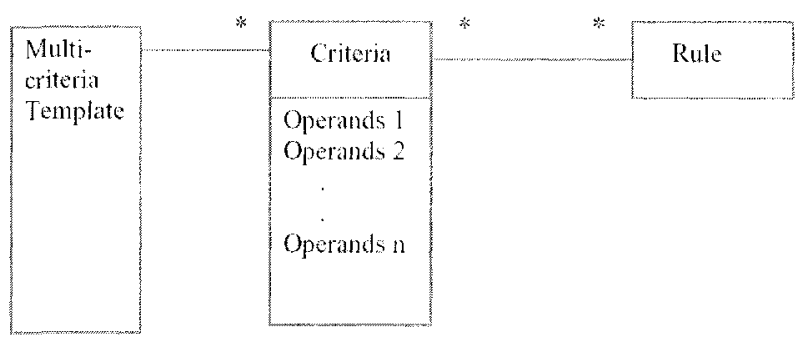

Figure 4. Relation between multi-criteria template and criteria

\section{(3) Analysis Operations and Criteria Management}

This part is the core of performance analysis. It answers for the request from the client or the application through API, and invoke other parts to accomplish analysis operation then return the result back to the relevant end. It also takes charge of managing and organizing criteria and Multi-criteria templates, make them related with knowledge, with which agent can communicate with other given agents to obtain information.

\section{(4) Information Collection}

The task of this part is simply gather data for performance analysis operation, yet it is so difficult to do. It should communicate with other business modules and gather information from the dynamic activities or results and preserved them to information base, prepared for the necessary of performance operation. Agent is a bridge of performance analysis system and other business modules.

\section{APPLICATION}

We use this framework of supply chain performance analysis system in the agentbased agile supply chain management system - a part of the project of APNM (Auto Parts Networked Manufacture System). JADE (Java Agent Development Framework) is used as a software framework to develop this agent-based ASCM and PAS. 


\subsection{JADE}

JADE (Java Agent Development Framework) is a software framework to aid the development of agent applications in compliance with the FIPA 2000 specifications for interoperable intelligent multi-agent systems (Bellifemine et al., 2001), JADE is fully development in Java and it based of the principles of interoperability, uniformity and portability, easy to use and pay-as-you-go philosophy. It is an Open Source Project, and the complete system and the white paper can be downloaded from JADE Web site.

\subsection{Performance Analysis System in ASCM}

The agent-based supply chain management system in APNM comprises of Sale agent, Warehouse agent, Transport agent, Product agent, Purchase agent and Finance agent. Implementing an order can be divided into two phases, these are:

1) Decision-making phase: In this phase, decision center estimates the available resource by communicating related agents, or forecasts the performance through the Performance Analysis System, and then decide if the orders are able to be carry out or not.

2) Implementing phase: In this phase, the orders will be carried out, and the performance analysis system obtains information from the process by agent. Practice performance can be evaluated in this phase.

The model of agent-based ASCM with Performance Analysis System shows as Figure 5 .

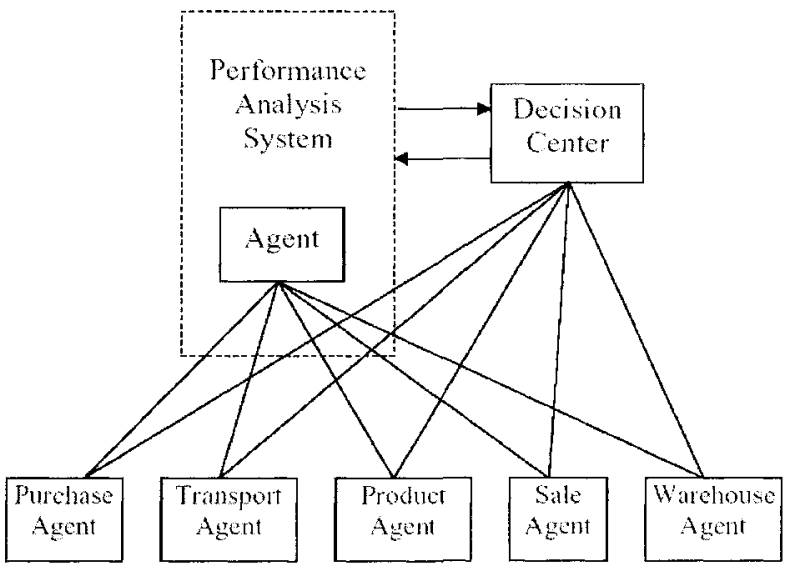

Figure 5. Performance analysis system in ASCM 


\subsection{Example}

The process will be demonstrated by an instance - eligibility rate of material to be put in storage, which reflects the quality level of the goods provided by supplier.

Presuming $\mathrm{Ri}$ is the eligibility rate of the given material, items i represents certain supplier $i$, it needs parameters as: the gross quantity of this material to be put in storage ( $\mathrm{Yi}$ ) and quantity of disqualification among them ( Di ). The formula is:

$$
\mathrm{Ri}=(\mathrm{Yi}-\mathrm{Di}) / \mathrm{Yi} * 100 \%
$$

Criteria and its formulae are initialized in the Criteria Base and managed by Center of Management and Operation; meanwhile, the type of the parameters is sent to knowledge Base as a rule. Performance Agent is listening the process of the business, when the event - putting material to storage - happened, performance agent sends message to the warehouse agent according to the rules in knowledge base to ask for $\mathrm{Yi}$ and $\mathrm{Di}$. The warehouse agent receives the request, and then sends back information with timestamp. Performance agent obtains information and reserves them to information base. It is convenient to pick up data in the given time.

While Center receives a request from client or application for eligibility rate of material to be put in storage in time segment T through API, it accepts and picks up the relevant data from Information Base in the light of its timestamp, and calculates using the formulae. Finally, the result will be returned.

\section{CONCLUSION}

Supply chain management has increasingly become the key strategic area which has direct impact over the success of any enterprise in today's highly competitive business environment, yet the performance analysis is the compass of the supply chain management, which evaluates the entire supply chain.

This paper has introduced supply chain performance analysis system, which is correlative with supply chain management but autonomic respectively. Criteria and multi-criteria are relatively flexible to different performance measures, so they demand autonomy. However, the data needed by performance analysis is sourced from the business of the supply chain. Information collection is vital, and agent is imported to settle this problem. We also have built the framework of the agent-based performance analysis system to meet the challenges in supply chain performance analysis, and use it in the project of Auto Parts Networked Manufacture System as an application.

\section{ACKNOWLEDGEMENT}

This work was supported by the project of Auto Parts Networked Manufacture System (National Development and Reform Commission People's Republic of China) and key laboratory symbolic computation and knowledge engineering of ministry of education. 


\section{REFERENCE}

1. Beamon, B.M., "Measuring Supply Chain Performance", International Journal of Operations and Production Management, 19(3), 275-292, 1999.

2. Bellifemine, F., Poggi, A., Rimassa, G., Rimassa,G., "JADE: A FIPA2000 Compliant Agent Development Environment ", Proceedings of the fifth international conference on Autonomous agents, ACM, Montreal, Quebec, Canada, 2001

3. Bourne, M., Mills, J., Wilcox, M., Neely, A., Platts, K., "Designing, implementing and updating performance measurement systems", International Journal of Operations \& Production Management, Vol.20, No.7, 754-771, 2000.

4. Chai YT, Liu Y, Agile Supply Chain Management, Publishing House of Qinghua University, Beijing, China, 2001

5. Fox, M.S., Barbuceanu, M., Teigen, R., “Agent-oriented supply-chain management”, Intemational Journal of Flexible Manufacturing Systems, 12(2/3), 165-199, 2000.

6. Huo JZ, Evaluating Enterprise Innovation: Integrated Supply Chain Performance and Evaluation, Henan People's Publishing House, Henan, China, 2001.

7. Julka, N., Srinivasan, R., Karimi, I., "Agent-based supply chain management-1:framework", Computers and Chemical Engineering", 26, 1755-1769, 2002.

8. Lambert, D.M., Cooper, M.C., "Issues in supply chain management", Industrial Marketing Management, 29(1), 65, 2000.

9. Liu $\mathrm{FH}$, Hai HL, "The voting analytic hierarchy process method for selecting supplier", International Journal of Production Economics, 97(3), 308-317, 2005.

10. Simichi, L.D., Kaminsky, P., Simichi, L.E., Designing and Managing the Supply Chain: Concepts, Strategies and Case Studies, Irwin/McGraw-Hill, Boston, 2000.

11. Suo HS, Jin YH, "The Application of Multi-Agent System in the Supply Chain Management", Computer Engineering and Application, 9-12, 2002.19, China.

12. Vrijhoef, R., Koskela, L., "The four roles of supply chain Management in construction", European Journal of Purchasing \& Supply Management, 6, 169-178, 2000.

13. Wooldridge, M., Jennings, N., "Intelligent agents: theory and practice", Knowledge Engineering Review, 10(2), 155, 1994.

14. Xu Y, Chen JL, Li ZB, Wang ZX, "Study and Realization on Framework of Universal Performance Evaluation System for Supply Chain", Research for computer Application, 152-154, 2004.

15. Yahya, S., Kingsman, B., "Vendor rating for an entrepreneur development programme: A case study using the analytic hierarchy process method", Journal of Operational Research Society, 50, 916-930, 1999.

16. JADE Web Site, http://jade.tilab.com/ 